\title{
Mujeres migrantes y violencia en Argentina: experiencias e implicancias en la salud/enfermedad/cuidado
}

\author{
Maria Florencia Linardelli ${ }^{1}$ \\ https://orcid.org/0000-0002-3250-2895 \\ ${ }^{1}$ Consejo Nacional de Investigaciones Científicas y Técnicas, Instituto de Ciencias Humanas, Sociales y Ambientales, \\ Universidad Nacional de Cuyo, Instituto de Estudios de Género y Mujeres, Mendoza, Argentina
}

\section{Mujeres migrantes y violencia en Argentina: experiencias e implicancias en la salud/ enfermedad/cuidado}

Resumen: Este artículo aborda las experiencias de violencia sufridas por mujeres originarias de Bolivia y del norte argentino durante sus recorridos migratorios asociados al trabajo agrícola en Argentina. El objetivo es analizar de qué modo esas vivencias fueron transitadas por las mujeres, qué incidencia tuvieron en su salud/enfermedad y cuáles fueron sus estrategias de cuidado para afrontarlas. A partir de un estudio etnográfico desarrollado entre 2014 y 2018 en la localidad de Ugarteche (Mendoza) se recabaron relatos de vida que permitieron identificar un complejo mapa de violencias acompañando los procesos de movilidad de estas trabajadoras. De la mano de perspectivas feministas y socio antropológicas de la salud, el trabajo argumenta que estas experiencias - que marcaron los cuerpos y la subjetividad de las mujeres - están ligadas tanto con la discriminación sexual y racista dirigida a las migrantes, como con los contextos de vulnerabilidad social en que ellas viven y trabajan.

Palabras clave: Violencia patriarcal. Racismo. Migraciones. Trabajadoras agrícolas. Salud.

\section{Mulheres imigrantes e violência na Argentina: experiências e implicações na saúde/doença/ cuidado}

Resumo: Este artigo aborda as experiências de violência sofridas por mulheres da Bolívia e do norte argentino durante suas trajetórias migratórias associadas ao trabalho agrícola na Argentina. O objetivo é analisar como essas vivências foram atravessadas pelas mulheres, quais os impactos que tiveram em sua saúde/doença e quais foram as estratégias de cuidado para lidar com elas. A partir de um estudo etnográfico desenvolvido entre 2014 e 2018 na cidade de Ugarteche (Mendoza), foram coletadas histórias de vida que permitiram identificar um complexo mapa de violências acompanhando os processos de movimentação dessas trabalhadoras. Apoiando-nos em perspectivas feministas e socioantropológicas da saúde, o trabalho defende que essas experiências - que marcaram os corpos e a subjetividade das mulheres - estão vinculadas tanto à discriminação sexual e racista dirigida a imigrantes como a contextos de vulnerabilidade social onde elas vivem e trabalham.

Palavras-chave: Violência patriarcal. Racismo. Imigrações. Trabalhadores agrícolas. Saúde.

\begin{abstract}
Migrant women and violence in Argentina: experiences and implications to health/illness/care Abstract: This article addresses the experiences of violence endured by women coming from Bolivia and northern Argentina during their migratory paths associated with agricultural labor in Argentina. The goal is to analyze how such life experiences were gone through by these women, the impact they had on their health/illness condition, and their care strategies for facing them. From an ethnographic study conducted between 2014 and 2018 in Ugarteche locality (Mendoza) we gathered the life stories of six women, which allowed identifying a complex map of violence accompanying the mobility processes of these women workers. Hand in hand with feminist and with socio-anthropological perspectives on health, this work argues that these experiences -which marked the bodies and subjectivity of women- are linked to sexual and racist discrimination directed at migrant women, and to the contexts of social vulnerability in which they live and work.
\end{abstract}

Key words: Patriarchal violence. Racism. Migrations. Agricultural laborers. Health.

Recebido em 21.10.2020. Aprovado em 15.12.2020. Revisado em 01.02.2021.

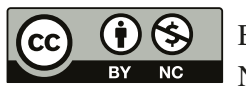

Este es un artículo publicado en acceso (Open Access) abierto bajo la licencia Creative Commons Attribution Non-Commercial, que permite su uso, distribución y reproducción en cualquier medio, sin restricciones siempre que $\sin$ fines comerciales y que el trabajo original sea debidamente citado. 


\section{Introducción}

En las últimas décadas, la violencia contra las mujeres migrantes constituye un tema de creciente interés en el campo de estudios migratorios. Distintas investigaciones señalan que la migración expone a las mujeres a diversas situaciones de violencia patriarcal: en ocasiones huyen de esta en sus países de origen, pero también las acecha durante el tránsito y es recurrente en el destino, agudizada por las extremas condiciones en que se realizan los desplazamientos, las políticas migratorias expulsivas y la persistencia de prácticas xenofóbicas y racistas en las sociedades de acogida.

En ese marco, este artículo aborda las experiencias de violencia, su incidencia en la salud/enfermedad y las estrategias de afrontamiento y cuidado vivenciadas por mujeres migrantes. Específicamente, focaliza en mujeres campesinas originarias de Bolivia y del norte argentino que realizan movilidades asociadas con el trabajo agrícola estacional cruzando distintas provincias argentinas. El estudio se basó en la estrategia metodológica de relatos de vida, reconstruidos en un trabajo de campo realizado entre 2014 y 2018 en la provincia de Mendoza, Argentina. Teóricamente el trabajo se nutre de perspectivas feministas y socio-antropológicas de la salud para analizar estas experiencias de violencia como vivencias singulares que se inscriben en procesos políticos, económicos y culturales más amplios.

Existen pocos estudios que vinculen la problemática de la violencia y la salud para analizar la situación de las mujeres migrantes que se realizan movilidades en el Sur global ${ }^{1}$. Frente a esta vacancia este trabajo aporta a una temática escasamente explorada y sugiere que la violencia patriarcal, xenofóbica y racista que sufren mujeres migrantes que se movilizan por territorios del agro argentino se vincula estrechamente con los contextos de vulnerabilidad social en que viven y trabajan. Asimismo, se busca hacer visible que ellas no soportan pasivamente esa situación, sino que desarrollan distintas estrategias de cuidado en procura de sustraerse de las agresiones y recuperarse de los daños que les provocan.

\section{Estrategia metodológica}

La temática abordada en este artículo se desprende una investigación más amplia sobre la relación entre condiciones de vida y trabajo y experiencias de salud/enfermedad/cuidado de mujeres migrantes que se insertan laboralmente en la agricultura de Mendoza. Durante el trabajo de campo de esa investigación, aunque no fue indagado explícitamente, surgió como un dato recurrente la violencia. En las diferentes entrevistas, las mujeres relataron recorridos migratorios atravesados por diversas formas de violencia patriarcal, xenofóbica y racista acontecida en hogares, comunidades, ámbitos laborales e instituciones públicas.

En términos generales, la investigación siguió un enfoque etnográfico con la finalidad de producir datos primarios que pudiesen dar cuenta de las perspectivas de las mujeres involucradas en el proceso. En el marco de ese enfoque, se priorizaron técnicas cualitativas específicas: relatos de vida y técnicas observacionales con diferentes grados de estructuración y participación. Durante cuatro años se realizaron observaciones en un poblado de trabajadores/as agrícolas migrantes y, en el mismo período, se reconstruyeron los relatos de vida de seis mujeres. La técnica del muestreo utilizada correspondió al muestreo intencionado o teórico. Se entrevistó a migrantes internas y originarias de Bolivia, mujeres de distintas edades — entre los 29 y los 57 años —, algunas trabajadoras activas y otras retiradas, migrantes de mediana y de larga permanencia.

El trabajo de campo de la investigación fue desarrollado en su totalidad en la localidad de Ugarteche entre 2014 y 2018. Este poblado se encuentra situado en el departamento de Luján de Cuyo, en el oasis Norte de Mendoza, a cuarenta kilómetros de la ciudad capital. Es una localidad de trabajadores/as agrícolas que se gestó de la mano de la migración sostenida de personas originarias de Bolivia. También aloja a migrantes provenientes del noroeste argentino, sin embargo, muchas/os estas/os últimas/as llegan en temporada de cosecha y luego retornan a sus provincias de origen.

\section{Herramientas teóricas para el análisis de la violencia contra mujeres migrantes}

En las últimas décadas, la violencia contra mujeres migrantes constituye un tema de creciente interés en el campo de estudios migratorios. Existe un cúmulo de investigaciones desarrolladas en distintos países receptores 
de migración, con diferencias según se localicen en el Norte o el Sur Global. Entre los primeros, los estudios situados en España señalan que las cifras de violencia contra mujeres migrantes son significativamente mayores que en mujeres nativas, situación que ha seguido una evolución creciente en los últimos años. Además, se abocan a analizar la violencia en el ámbito de la pareja y argumentan que existe una vulnerabilidad estructural de las mujeres migrantes frente a estas agresiones (Montañés y Moyano, 2006; Ladino, 2011; Arnoso et al. 2012; Bello Morales, 2013; Alencar-Rodrigues, Cantera y Strey, 2013; Mena Mosquera, 2015). En Estados Unidos, por su parte, las investigaciones focalizan en la violencia doméstica sufrida por migrantes latinoamericanas. Sostienen que las políticas de control de la inmigración comprometen la seguridad de las migrantes, quienes además afrontan diversas desigualdades cuando acuden en búsqueda de ayuda a las instituciones estadounidenses, situación que las empuja a desarrollar múltiples estrategias para sobrevivir (Erez y Adelman, 2009; DeusdadAyala, Moya y Chávez-Baray, 2012; Silva-Martínez, 2012).

Uno de los países del Sur Global con mayor cantidad de investigaciones sobre el tema es México, donde existen estudios que indagan la violencia y la dominación de género, étnica y de clase que pesa sobre las mujeres indígenas implicadas en movimientos migratorios internos asociados al trabajo agrícola (Lara Flores, 2003). Otros trabajos recorren las diversas formas de violencia a las que se ven expuestas mujeres indígenas -mexicanas y provenientes de distintos países de América Central- al transitar por México para ingresar a Estados Unidos (Ruiz, 2004; Suárez Escobar y Durand Alcántara, 2014; Morett Sánchez y Pizano, 2015). Algunos de estas pesquisas examinan la violencia contra las migrantes a la luz de las restrictivas políticas migratorias y las relaciones internacionales entre estos países (Pérez Oseguera et al., 2008; Woo Morales, 2004). En Argentina, un estudio pionero en el tema fue realizado con migrantes bolivianas que trabajaron y vivieron en talleres textiles clandestinos. Este trabajo evidenció que ellas sufren con mayor intensidad y peores consecuencias las distintas situaciones de violencia (estructural, física, psicológica) y de riesgo para su salud presentes en el modo de vida/trabajo/vivienda en los talleres (Goldberg, 2013). También se dispone de investigaciones que analizan la violencia doméstica contra migrantes bolivianas y señalan la naturalización de este fenómeno por parte de las propias migrantes (Buccafusca, 2010).

Diferentes autoras polemizan con la utilización de los conceptos de víctima/vulnerable en las investigaciones sobre violencia y migraciones, por cuanto homogenizan a las migrantes, contribuyen a construir perfiles rígidos sobre ellas, condicionan el acceso igualitario a los derechos y favorecen políticas persecutorias de las sujetos que debieran proteger (Albertín, 2016; Cea Merino y Montenegro-Martínez, 2014; González-Prado y Bacci-Tamburlini, 2014). Estas investigadoras advierten que algunos estudios criminalizan y estereotipan las sociedades de procedencia de las migrantes, al tiempo que ocultan la responsabilidad de la sociedad de acogida en la aparición de la violencia. Además, argumentan que considerar a las migrantes como víctimas invisibiliza su autonomía y protagonismo en los procesos migratorios.

En acuerdo con esos planteos, en este trabajo se considera que la violencia hacia las mujeres es un mecanismo de reproducción de las sociedades patriarcales y constituye una problemática social, estructural y política, antes que un problema asociado con la presunta vulnerabilidad de las sujetos que la padecen. Rita Segato (2003, p. 107) sostiene que la jerarquía patriarcal depende "de la repetición diaria, velada o manifiesta, de dosis homeopáticas pero reconocibles de violencia", que recuerdan a las mujeres su lugar en la sociedad. Para la autora, la violencia es una faceta constitutiva de las relaciones de género en su aspecto percibido como "normal". Es decir, no se trata de un fenómeno extraordinario o una tragedia, sino que sus expresiones extremas -violencia física, sexual y asesinato- forman parte de un gradiente de situaciones más solapadas y de difícil percepción, que se confunden en el contexto de relaciones, incluso, aparentemente afectuosas (Segato, 2003).

Los feminismos antirracistas señalan que la violencia patriarcal no afecta a todas las mujeres del mismo modo. Kimberlé Crenshaw (1998) destaca que el maltrato contra las mujeres de color frecuentemente resulta de la intersección de patrones racistas y sexistas y, por tanto, su experiencia no está determinada por los márgenes tradicionales de la discriminación de género. La autora postula que la agresión física sufrida por las mujeres de color es la manifestación más inmediata de la subordinación en la que viven, vinculada con el desempleo, el trabajo precario y la pobreza. Por tanto, al analizar la violencia patriarcal que se dirige a las migrantes debe reconocerse que las mujeres no experimentan la misma opresión de género, sino que ésta se transforma según diferentes contextos y de acuerdo con "múltiples pertenencias" (Anthías, 2006). En particular, es menester destacar el lazo que existe entre estigmatización, discriminación y violencia, porque en dicho vínculo descansa la eficacia de esta última: 
Los procesos de estigmatización no pueden comprenderse fuera de su ligazón a prácticas de discriminación social que afectan la vida y los procesos identitarios de vastos conjuntos sociales. Estas prácticas [...] articulan dispositivos de sujeción y opresión que se traducen en diversas formas de violencias y abiertas persecuciones contra sujetos y grupos (Grimberg, 2006, p. 37).

En este marco, resulta útil recuperar la noción de contextos de vulnerabilidad social (Bronfman et al., 2003 ) referida a las configuraciones socioculturales resultantes de la interacción entre diversos actores sociales, políticos, económicos y sanitarios, que constituyen la trama en que se desenvuelve la vida cotidiana de algunos grupos sociales. Migrar, trabajar, reproducir la vida en contextos de vulnerabilidad expone a riesgos sanitarios que no dependen de comportamientos ni características individuales. Esta noción cambia el foco de la cuestión, ya que no se trata de identificar las características de ciertos grupos a los que se considera vulnerables (sea por la desprotección frente a potenciales daños de salud o amenazas a la satisfacción de sus necesidades y al respeto de sus derechos humanos) sino de analizar contextos determinados por las relaciones entre diferentes actores sociales.

\section{"Porque somos extranjeras mucha gente se abusa". El complejo mapa de violencias cotidianas contra las mujeres migrantes}

En los relatos que siguen se verá que las agresiones en el entorno familiar y de la pareja resulta una de las manifestaciones de un mapa más complejo de violencias. La violencia institucional, la discriminación, la estigmatización y el abuso sexual en el trabajo, el acoso y hostigamiento en sus comunidades, conforman un entramado cotidiano de agresiones contra las mujeres migrantes. A fines de organizar la diversidad de narrativas se presentan las distintas experiencias de acuerdo con el ámbito en el que acontecieron: los espacios laborales, las relaciones familiares, las instituciones públicas y los espacios comunitarios.

Las migrantes expresan que los ámbitos laborales constituyen el escenario de distintas formas de violencia - psicológica, económica y sexual — ejercida primordialmente por empleadores, intermediarios (cuadrilleros) y compañeros/as de trabajo, identificados como "los criollos" o "los argentinos".

Te dicen "esta boliviana de mierda que va adelante y nos hace quedar mal, por qué no se va a su país". Cuando te toca un cuadrillero que es criollo ¡te apura, te apura! y dice "estos bolivianos de mierda, para qué me los mandan”. Cuando me pasa eso, les digo "Soy boliviana y soy orgullosa ¡soy negra, sí, soy negra! todos somos únicos, cada persona es única. Yo aquí vine a trabajar por necesidad y creo que tú también vienes por necesidad. Porque nosotros trabajamos no tenemos que ser discriminados, porque somos personas como ustedes y como todos" [...]. Cuando fui empleada doméstica trabajábamos tres mujeres, como nosotras éramos bolivianas comíamos en un patio donde estaban los perros. Usted dígame ¿está bien eso? Podíamos comer en cualquier rincón, pero no donde estaban los perros, donde hacían pis, donde hacían todo ¿Qué puedo pensar? A mi manera de ver, porque somos extranjeras mucha gente abusa. En otra casa que trabajé de empleada el hijo nos quiso violar, a mí y a la chica que cocinaba. Salimos corriendo a las dos o tres de la mañana. No nos pagaron nunca en esa casa, porque la mujer dijo que habíamos dejado abandonado nuestro trabajo. Son así porque somos extranjeras, por eso nos tratan así. No seguí mucho tiempo en las casas de familia ¿quién puede aguantar? (Sonia, 35 años).

Cuando trabajaba en el tabaco el patrón tenía un hermano, que era muy atrevido también... me llevaba a descargar la estufa y cuando terminaba me decía "bájate pues", al bajarme me empezaba a manosear... y alguien le contó al patrón, yo tenía miedo de contarlo. Pensaba que me iban a dejar sin trabajo y no hablaba, yo me callaba todo lo que me manoseaban. Me daba miedo ir a trabajar con él, pero tenía que ir porque yo necesitaba. Sino ¿dónde iba a ir a trabajar? (Rita, 37 años).

En el marco de las relaciones familiares, la violencia física y psicológica se hace presente en la cotidianidad y suscita diversas estrategias individuales y colectivas para afrontarla. Figuras masculinas próximas como tíos, maridos o allegados propician las "dosis necesarias" de violencia para sostener el mandato patriarcal. 
Una vez nada más me pegó mi marido. Nos peleamos por un chisme que le llevaron y él me metió una piña en la cara. Yo estaba embarazada de cinco meses, con la piña me tiró al piso. Cuando me levanté, agarré una jarra de vidrio que tenía al lado y le metí un golpe en la cabeza que casi lo maté. Le dije "a mí no me vas a levantar la mano por un chisme, primero preguntame cómo fue la cosa, no tenés ningún derecho de pegarme" ¿Sabe lo que había pasado? Yo le había dicho a su hermano que quería ser chacarera yo con mi marido, allá en Maipú. Su hermano cuando se encontró a mi marido le dijo “¿Qué, te va a mandar tu mujer? Te va a llevar a Maipú habiendo tanta tierra acá”. Por eso me pegó, por querer ir a hacer chacra allá en Maipú (Alba, 52 años).

Yo ahora estoy separada, él me pegaba cuando estábamos juntos, eso siempre me dio mucha bronca y le decía "ya vas a ver un día te voy a agarrar". Él se reía y me decía "¿Qué me vas a hacer? Mirá lo que sos, no podés hacerme nada". Me daba tanta bronca porque, es verdad, no se puede contra la fuerza de un hombre. Pero un día me largó con una herramienta y me cortó la mejilla ¡Tenía una furia yo! y me fui encima de él, lo agarré de abajo, lo apreté hasta que se arrodilló y me pidió que lo soltara. Así hay que agarrar a los hombres, no hace falta tanta fuerza. Después de eso ya no fue lo mismo. Pero también cuando mis hijos crecieron cambiaron las cosas, ellos empezaron a meterse y le decían “¿qué le hiciste a la mamá que está llorando?" (Sonia, 35 años, registro de campo, diciembre de 2015).

A mí me cambió el grupo de tejido² , lo que charlamos. Desde ahí yo empecé a decir ¿por qué mi marido me tiene que tatar así? Yo no me tengo que dejar humillar. No puede gritarme, maltratarme o humillarme. Desde que hablamos con Caro (coordinadora del taller de tejido) yo no me dejé humillar más (Sandra, 29 años).

Desde la experiencia de las mujeres entrevistadas, el ámbito comunitario y las relaciones vecinales también resultan espacios donde se hacen presentes prácticas racistas y xenofóbicas. Son sus vecinos/as argentinos/as quienes ejercen distintas formas de estigmatización y discriminación, las insultan, descalifican y maltratan.

Los argentinos, nos tratan mal. Mi vecina, me dice boliviana mugrienta. Y yo les digo a mis hijos ¿no habrá justicia para eso? Sí, yo soy boliviana, si mi papá no me hubiera traído no hubiera conocido la Argentina ¿Cómo no me fui? Estoy cansada de la gente que dice cosas, me da rabia. Yo decía cuando era chica "¿por qué nos dicen bolivianos mugrientos?, si no somos sucios”. Por eso no salgo, casi nunca, para ir ahí al grupo de tejido si pero, no soy de salir mucho. Yo estoy cansada con la gente que dicen cosas, me da rabia (Alba, 52 años).

Cuando llegué a Mendoza me empezaron a decir boliviana. En todos lados que te miran feo, por cómo estás vestida. Por ahí nosotros no hablamos como ellos hablan acá. No solo como te vestís, sino como hablás, eso se nota mucho. Nos tratan mal, nos dicen bolivianas. Y yo no les digo nada. Yo nací en Salta (Argentina) y no hablo quechua como las paisanas, entonces me dicen: "esta boliviana de mierda, qué se hace la argentina si es boliviana". Yo no digo que no yo soy del campo. No soy de la ciudad, que hablan bien, yo aprendí eso (Rosa, 40 años).

En distintas oportunidades se indagó con las mujeres participantes del estudio si alguna vez habían acudido a instituciones públicas en búsqueda de asesoramiento o ayuda ante situaciones de violencia. En general, las respuestas fueron negativas y surgieron alusiones sobre la ineficacia de los espacios institucionales existentes. Algunas de las mujeres manifestaron tener temor de acudir a instituciones públicas puesto que podían ser cuestionadas en su rol materno o por la posibilidad de que la situación se complejice.

A la asistente social de la sala no he ido porque me han dicho mis amigas que no vaya. Es buena y trata de ayudarte, pero al final termina complicando más las cosas (Jessica 19 años, registro de campo, 2016).

Cuando fuimos a denunciar (por violencia) al marido de mi hija nos mandaron a la comisaría de Luján (a 20 kilómetros de su casa). Ahí tenés que esperar muchísimo para que te atiendan. Nos tomaron la denuncia 
a la una de la mañana y a esa hora ya no tenía micro para volver así que tuve que pasar la noche con mi bebé y mi hija en la comisaría. Ni hablar de la plata para el micro, que no siempre tenemos. Además, si te están pegando, si te están robando, no viene la policía, no se meten cuando le pegan a un boliviano (Rita, 37 años, registro de campo de 2016).

La inacción policial ante los ataques dirigidos a migrantes bolivianos/as abre otra dimensión a explorar referida a la violencia institucional. Esto es, que las instituciones públicas no solo se presentan como lugares ineficaces, sino que también en ocasiones ejercen, reproducen y/o amparan las violencias patriarcales, racistas y xenofóbicas que se dirigen a las migrantes originarias de Bolivia y del noroeste argentino.

Cuando vivía en la DINAF ${ }^{3}$ fue muy difícil. Todos eran criollos en esas casas, o sea todos eran argentinos. Me hacían burla, me molestaban todos los días, no podía estar tranquila. Me decían que era una negra de mierda, una boliviana que venía a comer la comida de los argentinos, que les sacamos la plata y el trabajo. Yo les decía "con mucha honra, porque yo vengo a trabajar acá, no vengo a robar" (Sonia, 35 años).

Cuando cruzo a Chile para comprar ropa los gendarmes nos dicen "los bolivianos solamente están trabajando como burros, pero no entienden nada" o "son tercos los bolivianos" y para mí eso sería discriminación. Siempre con la policía hay mucha discriminación (Sandra, 29 años).

De los múltiples relatos hasta aquí presentados es necesario destacar que estas experiencias — además de constituir dolorosas vivencias singulares — se inscriben en lógicas sociales, políticas, económicas y culturales más amplias. La discriminación que padecen en Argentina quienes son originarios/as de Bolivia ha sido analizada por autores/as que indican que estos grupos afrontan procesos de racialización y estigmatización a partir de ciertos rasgos fenotípicos asociados con la “indianidad”. Por esta vía, también se define como extranjeros/as a sus hijos/as, aunque hayan nacido en Argentina, y a las/os migrantes internos que provienen del noroeste del territorio nacional, proceso denominado como desnacionalización o extranjerización (Briones, 2005; Mallimaci, 2012). Tanto la racialización, como la extranjerización realizadas por algunos sectores de la sociedad argentina, para Alejandro Grimson (1999), se apoyan y refuerzan desigualdades de clase, además de nacionales o étnicas. El autor indica que el uso de la categoría "boliviano/a", en el marco de estos procesos de estigmatización, no designaría tanto a quienes nacieron en el vecino país, como a quienes muestran un determinado tipo de inserción y comportamiento laboral.

La discriminación racial, nacional y de clase, expresada en la subordinación histórica de los/as migrantes bolivianos/as en el mercado de trabajo, se profundiza cuando de mujeres se trata. Las prácticas xenofóbicas y racistas se entrecruzan con la violencia patriarcal y redundan en que la violencia contra las mujeres migrantes adquiera formas específicas. Algunas de las entrevistadas debieron soportar situaciones de violencia sexual en el entorno laboral por temor a perder el empleo y pocas de ellas recibieron ayuda institucional para atender estas problemáticas. Otras aludieron que el trazado de su recorrido migratorio se vio afectado por la necesidad de escapar de los perpetradores de las agresiones. En los hogares, el enfrentamiento abierto con sus parejas fue la única alternativa para lidiar con la violencia patriarcal. En general, fueron los lazos con otras mujeres migrantes los que las protegieron y les permitieron enfrentar distintas agresiones.

Como puede apreciarse, el hecho de que las migrantes se vean afectadas por este entrecruzamiento de violencias, antes que reflejo de su vulnerabilidad, se vincula principalmente con los contextos de vulnerabilidad social en que migran y trabajan. La trama que tejen del racismo en su comunidad y en las instituciones públicas argentinas, la subordinación económica en el mercado de trabajo y la violencia patriarcal en sus relaciones familiares muestra como interactúan y se potencian distintos actores, que con sus acciones y omisiones dibujan el complejo mapa de violencias al que aludimos inicialmente.

\section{“A una le causa mucho daño". Las violencias y la salud-enfermedad-cuidado}

Para los estudios feministas múltiples dolencias transitadas por las mujeres encuentran su fundamento en las relaciones patriarcales. Ciertas problemáticas de salud distintivas y frecuentes entre las mujeres son atribuibles a una posición social subordinada, antes que a especificidades anatómicas o fisiológicas. 
Concretamente, la incidencia de la violencia patriarcal suscita múltiples padecimientos físicos y psicológicos en ellas. Las investigaciones disponibles asocian este fenómeno con cuadros depresivos, cefaleas, aparición o agudización de eventos alérgicos, trastornos menstruales, pérdida del deseo sexual, infecciones urinarias, embarazos no planificados e hijos/as con bajo peso al nacer (Tájer, Gaba y Reid, 2011; Blanco et al., 2004).

Las diversas narrativas expuestas hasta aquí brindan algunas evidencias sobre la forma en que distintas violencias inciden en la salud de las mujeres migrantes. En particular, un relato reconstruido en nuestro trabajo de campo condensa las distintas temáticas que aquí analizamos: tanto el impacto de las violencias en la salud y el cuerpo de las mujeres, así como también las estrategias desplegadas para afrontar los daños que provoca.

A veces cuando una viene de Bolivia muchas cosas pasan. Me escapé de la casa de mi tío porque él me pegó y me pateó en el piso... esa noche me violaron. Yo creo que mi tío mandó al hombre que me violó. Después de eso tenía toda la espalda golpeada. Me dolía todo el cuerpo, un poco también por la pelea con mi tío. No podía hablar, solo lloraba. Pasé el día siguiente sentada al sol, sentía mi cuerpo re mal, no podía hacer nada, no tenía fuerza digamos. Cuando encontré a mi hermano me llevó a pasar la noche a un galpón, con unos matrimonios para que me cuidaran. Una señora me llevó con ella y me prestó un colchón para dormir. No podía dormir del dolor de espalda que tenía, entonces la señora agarró un jarro de aluminio, en ese le vació alcohol y sal, le hizo hervir y con eso me lavó el cuerpo. Me dijo que mi espalda estaba moreteada por los golpes que recibí. Lloraba mucho la señora cuando me lavaba.

\begin{abstract}
Antes no me gustaba hablar nada de eso, porque me sentía re mal. Pero después una vuelta en la finca nos sentamos entre mujeres y empezamos a hablar. Una de las chicas empezó a contarme que su mamá había ido a tener su hermanita al hospital y su papá se había abusado de ella. Y así, empezamos a contarnos, ella me contaba llorando, la otra contaba llorando, yo contaba llorando también lo que me había pasado... y desde ahí ya nunca más me da cosa para contar. Yo pienso que todo lo que tenía guardado le saqué afuera. Vi que no me pasó únicamente a mí, capaz lo de mi compañera de trabajo fue más feo todavía, porque fue su papá, no otra gente. Me puse a pensar eso y lo extraño es que a las tres mujeres que estábamos ahí, las tres pasamos las mismas situaciones casi. De ahí me siento tranquila, libre, de ahí pude contar, ya no tengo miedo, ni dolor. Pero antes no podía hablar de eso. Porque a veces a una le causa mucho daño... a veces nos cuesta recuperar, por lo menos a mí me costó muchísimo. Tenía terror que me pudiera pasar eso, apenas veía los a hombres me daba miedo, aunque me esté mirando ya, estoy sintiendo, parece que me esté tocando, que me está atacando. Pero después de que charlamos, no digo que no tengo miedo, pero ya no tanto como antes, porque el miedo me dominaba antes, me ganaba, no podía salir adelante. Pero ahora ya no (Rita, 37 años).
\end{abstract}

Este relato, junto con las narrativas presentadas en la sección anterior, exhiben distintos asuntos a considerar. Por una parte, las mujeres refieren que las múltiples situaciones de violencia suscitaron sentimientos de dolor, rabia, furia, tristeza, bronca, cansancio, miedo y terror. Estas emociones, si bien se asocian manera precisa con los acontecimientos experimentados, las acompañaron durante largos períodos de sus trayectorias y requirieron de arduos y prolongados procesos para recuperarse. Algunas mujeres identificaron con minuciosidad cómo estas experiencias incidieron en su vida cotidiana, en sus relaciones interpersonales, en el desempeño de su trabajo y en sus decisiones migratorias. Para otras, no se trata de un asunto ubicado en el pasado, sino que el temor reaparece en su cotidianidad y se repone ante situaciones que identifican como amenazantes. Hay quienes manifestaron especial cansancio y agobio vinculado con las situaciones de discriminación en sus comunidades, que han conducido a limitar las interacciones vecinales. Cada una de estas vivencias sugiere la afectación de distintas áreas de la vida cotidiana y redunda en una disminución de su calidad de vida.

Por otra parte, cabe mencionar los diferentes daños y lesiones provocadas por agresiones físicas y sexuales, como hematomas, cortes, dolores corporales y pérdida de energía o de vitalidad. Estos padecimientos recibieron la atención y el cuidado del entorno próximo de las mujeres, especialmente de amigas, familiares o allegadas. En ningún caso las mujeres acudieron a instituciones sanitarias para recibir atención por estas dolencias, debido a la aprehensión que suscitan las posibles intervenciones tutelares, pero también porque las instituciones sanitarias, con sus acciones y omisiones, resultan espacios reproductores de la violencia.

Consideramos que las respuestas estatales para prevenir, sancionar y erradicar la violencia patriarcal participaron en la producción de contextos de vulnerabilidad social para las mujeres migrantes. En Argentina, 
estas políticas públicas, tras décadas de omisiones, resultan esporádicas y poco sistemáticas. Además, el escaso presupuesto en materia de prevención y la ineficacia judicial en la investigación y la sanción de feminicidios y otras violencias, han contribuido a crear un clima de impunidad para los atacantes. En particular, las instituciones de atención médica resultan espacios de reproducción de violencias patriarcales que atentan contra la autonomía de las mujeres, las infantilizan y las tornan objeto de tratos crueles y degradantes, como se ha documentado en el caso de la atención obstétrica (Canevari, 2011).

Justamente, durante el trabajo de campo pudimos observar que la impericia estatal se agudiza frente a las mujeres migrantes, por la articulación de prácticas de discriminación sexual y racial. De un lado, en las instituciones subyace su consideración como menos legítimas que las mujeres nativas para solicitar servicios públicos. De otro, existe un prejuicio persistente entre los/as agentes institucionales que presupone que la violencia contra mujeres provenientes de culturas andinas es un rasgo típico de sus grupos de origen, lo que contribuye a naturalizar las agresiones que sufren en su vida cotidiana. Además, el maltrato recibido por las migrantes en las instituciones de salud resulta una de las razones preponderantes por las que ellas perciben tales ámbitos como lugares de encierro y temor, que procuran evitar tanto como sea posible. Sus apreciaciones muestran que la relación con los/as trabajadores/as del sistema de atención médica también constituye un espacio cruzado por prácticas racistas y xenofóbicas.

Cada vez que iba a tener familia me bañaba, me refregaba los pies con piedras, porque hay enfermeras que dice que una es sucia: "boliviana sucia", te dicen, siempre hay esa discriminación. Por eso yo iba siempre bien limpita, bien cambiadita, la ropa del bebé bien lavadita, ordenadita, para que no me digan nada (Alba, 52 años).

Los argentinos te atacan y te humillan mucho, te sacan de la fila de los turnos en el centro de salud. Y los que dan los turnos defienden al que es de acá, les creen a ellos. La asistente social me dijo que los bolivianos venimos porque acá es todo gratis, el centro de salud y el hospital, y en Bolivia es todo pagar. Pero yo nunca vine porque es gratis acá, yo vine por trabajar, venimos a ganar plata, no porque fuera gratis atenderse (Sandra, 29 años).

La pediatra solamente con verte la piel piensa "esta no es una argentina". Yo creo que la manera como ellos se expresan es como que te quieren humillar, es feo. Como digo yo, seamos blancos o negros somos personas humanas. Y mucha gente no lo ve eso, eso es lo que me da bronca. Yo a veces veo que en este centro de salud (de Ugarteche) que hay más gente boliviana, que vive en las fincas o no hablan bien el castellano. Digamos, viene una señora con un niño que tiene fiebre y con el otro que está que devuelve y devuelve, en el aguayo tiene cargado un bebé chiquito que ya no da más. Y le dicen "mirá, no alcanzan los turnos, volvé mañana". Ella les explica "vengo de tal lugar, no hay micro, no tengo como venirme, anoche me quedé y no me quieren atender". Yo pienso que ipor favor! que la atiendan, la madre está llorando y nada. Cuando veo eso me da impotencia, me da bronca. Porque, una, es madre, otra, es mujer. La otra situación es que vive en la finca, no tiene cómo llegar, no tiene recursos, no tiene una moto, ni quizás una bicicleta ¿Cómo hace para venir? ¿No entienden eso? Digo yo, porque le ven la piel, ven que la mujer no se puede defender, porque ven en la piel que es de otro país, que por eso es la discriminación ¿O son racistas? (Sonia, 35 años).

En estos contextos, las mujeres despliegan diversas estrategias individuales y colectivas para afrontar la violencia y la discriminación. A veces, evitan las instituciones de salud tanto como sea posible. En ocasiones, se enfrentan abiertamente con los/as agentes institucionales. También despliegan lazos de solidaridad con sus pares cuando advierten situaciones injustas.

A la sala no voy. Cuando tuve a mis hijos fui a llevar a los niños no más, pero yo por mí no... En los partos sí iba al hospital, porque si no me iba a morir acá. Después de eso nunca más fui. No quería llegar al hospital, no era de esas mujeres que le dolía apenas la panza para tener familia e iba. No, yo esperaba hasta el último momento, porque tenía niños chicos, mi marido trabajaba y no tenía a quién dejarlo. Con mi último hijo me escapé del hospital, le dieron el alta al nene y a mí no, así que yo dije "me voy a ir 
igual”. Fue por mis hijos, me daban pena, eran chiquitos, por ellos me escapé. Nunca más volví al hospital desde esa vez (Alba, 52 años).

\begin{abstract}
Yo se los he dicho a los médicos en la cara: "mirá cómo está esa mujer con tres niños ¿por qué no la pueden atender? yo no me voy a hacer atender, pero atiéndanla a ella por favor. La mujer les está explicando que no se puede mover porque vive lejos en la finca. Usted dígame ¿cómo se ha hecho para venir y cómo está ese niño?" Es lo que yo les pregunto. Yo creo que como ella no se puede defender, por eso se aprovechan. Yo se los digo "¡Ustedes, no se pasen, porque todos somos personas! Ella viene acá porque necesita ayuda y ¿qué hacen ustedes? ¿por qué es extranjera? ¡No! todos somos personas humanas”. Cuando son personas que van bien vestidas que hablan bien, yo ahí no me meto. Pero yo he visto mujeres en situaciones desesperadas y como me acuerdo por lo que pasé cuando llegué, las trato de ayudar (Sonia, 35 años).
\end{abstract}

Hasta aquí se pudo visualizar que, frente a los padecimientos provocados por la violencia y ante la carencia de espacios institucionales a los que acudir, las mujeres migrantes desarrollan estrategias activas, individuales y colectivas, para preservarse y proteger a otras. Sea mediante la posibilidad de compartir sus experiencias, el enfrentamiento con quienes las golpean y humillan o bien la huida de ciertos entornos violentos y de los perpetradores de las agresiones, los relatos exhiben formas de resistencia que, aunque no trastocan las relaciones estructurales que las constriñen, permiten cuestionar la consideración de estas mujeres como víctimas y vulnerables. Estas prácticas, a su vez, muestran tramas colectivas y horizontales de cuidado frente a la violencia que permiten sortear las críticas situaciones que enfrentan.

\title{
Consideraciones finales
}

Las violencias patriarcales y racistas contra las mujeres migrantes emergieron como un dato persistente en el trabajo de campo. Un complejo mapa de violencias integrado por agresiones en el entorno familiar y la pareja, por discriminación y estigmatización en las instituciones, por abuso sexual en el trabajo y hostigamiento en sus comunidades, fue tomando forma en las narrativas. En vínculo con estas experiencias surgieron distintos padecimientos psicofísicos. Desde sentimientos de dolor, rabia, furia, tristeza, bronca, cansancio, miedo y terror, sensaciones de pérdida de la vitalidad y dolor corporal, hasta lesiones provocadas por agresiones físicas y sexuales. Frente a las violencias las mujeres desplegaron estrategias individuales y colectivas, para protegerse y proteger a otras: compartir sus experiencias, enfrentar a los perpetradores de los golpes y las humillaciones, huir de los agresores y evitar ciertos ámbitos violentos.

En particular queremos destacar las formas de afrontar la discriminación o el maltrato en los servicios médicos: el acto de "escaparse" del hospital, discutir con el personal de salud o ceder turnos a sus paisanas son formas de hacerse oír en un contexto en el que las palabras de las mujeres no resultan audibles para las instituciones. No buscamos romantizar la experiencia de tener que huir de un espacio que debiera ser de cuidado, ni el tener que enfrentarse a quienes deben brindar atención. Sin embargo, queremos destacar que las mujeres no permanecen estáticas o sumisas frente a la violencia ni ante la discriminación que les dirigen.

En sus estrategias de afrontamiento hallamos una clave que permite discutir con el supuesto sostenido por algunas investigaciones sobre la presunta vulnerabilidad de las mujeres migrantes a la violencia. Si bien puede que se vean más afectadas que las mujeres nativas por ciertas agresiones, antes que reflejo de su vulnerabilidad, esto es un resultado tanto de la discriminación sexual y racista contra las migrantes, como de los contextos de vulnerabilidad social en que viven y trabajan.

\section{Referencias}

ALBERTÍN, P. (2016). Subjetividades tejidas en historias de violencias de género y procesos migratorios: lugares liminales de transformación. Psicoperspectivas, 15(1), 66-78.

ALENCAR-RODRIGUES, R., CANTERA, L. y STREY, M. (2013). Violencia de género contra mujeres inmigrantes: un estado del arte. La Ventana, (37), 41-69. 
ANTHÍAS, F. (2006). Género, etnicidad, clase y migración:interseccionalidad y pertenencia translocalizacional. En P. Rodríguez, Feminismos periféricos (pp. 49-68). Granada: Editorial Alhulia.

ARNOSO, M. et al. (2012). Mujer inmigrante y violencia de género: factores de vulnerabilidad y protección social. Migraciones, 32, 169- 200.

BELLO MORALES, S. A. (2013). El contexto migratorio como determinante de la violencia de género en mujeres inmigrantes. Tesis doctoral, Universidad de Alicante, Alicante.

BLANCO, P. et al. (2004). La violencia de pareja y la salud de las mujeres. Gaceta Sanitaria, 18(4),182-188.

BRIONES, C. (2005). Formaciones de alteridad: contextos globales, procesos nacionales y provinciales. En C. Briones, Cartografías Argentinas. Políticas indigenistas y formaciones provinciales de alteridad (pp. 9-40). Buenos Aires: Antropofagia.

BRONFMAN, M. et al. (2003). Migración, género y SIDA: contextos de vulnerabilidad. Género y Salud en Cifras, 1(3), 8-12.

BUCCAFUSCA, S. (2010). Un silencio que aturde. Mujeres bolivianas y violencia doméstica. Temas de mujeres, 6(6), 31-42.

CANEVARI, C. (2011). Cuerpos enajenados. Experiencias de mujeres en una maternidad pública. Santiago del Estero: Barco Edita. CEA MERINO, P. y MONTENEGRO-MARTÍNEZ, M. (2014). Violencia de género en la pareja contra mujeres inmigradas en España. Quaderns de Psicologia, 16(1), 167-180.

CRENSHAW, K. W. (1998). Cartografiando los márgenes: Interseccionalidad, políticas identitarias y violencia contra las mujeres de color. En R. Platero, Intersecciones: cuerpos y sexualidades en la encrucijada (pp. 87-122). España: Bellaterra.

DEUSDAD-AYALA, B., MOYA, E. y CHÁVEZ-BARAY, S. (2012). Violencia de género y mujeres migrantes en la frontera: el caso de El Paso, Texas. Portularia, XII(Extra), 13-21.

EREZ, E. y ADELMAN, M. (2009). Intersections of Immigration and Domestic Violence. Voices of Battered Immigrant Women. Feminist Criminology, 4(1), 32-56.

GOLDBERG, A. (2013). Trayectorias migratorias, itinerarios de salud y experiencias de participación política de mujeres migrantes bolivianas que trabajaron y vivieron en talleres textiles clandestinos del Área Metropolitana de Buenos Aires, Argentina. Anuario Americanista Europeo, (11), 199-216.

GONZÁLEZ-PRADO, P. y BACCI-TAMBURLINI, M. (2014). Mujeres-vulnerables, mujeres víctimas. Explorando perspectivas críticas sobre categorizaciones y prácticas institucionales en contextos de violencia patriarcal y migración. Revista Tramas/Maepova, 3(1), 121-135.

GRIMBERG, M. (2006). Contextos de vulnerabilidad social al VIH/SIDA en América Latina. Desigualdad social y violencias cotidianas en jóvenes de sectores subalternos. Thule. Rivista italiana di studi americanistici, (20/21), 31-54.

GRIMSON, A. (1999). Relatos de la diferencia y la igualdad. Los bolivianos en Buenos Aires. Buenos Aires: Eudeba.

LARA FLORES, S. M. (2003). Violencia y contrapoder: una ventana al mundo de las mujeres indígenas migrantes, en México. Revista Estudos Feministas, 11(2), 381-397.

LADINO, M. T. (2011). La migración como escenario para la comprensión de la violencia de género entre migrantes internacionales. Amérique Latine Histoire et Mémoire. Les Cahiers ALHIM, (21).

MALLIMACI, A. I. (2012). Revisitando la relación entre géneros y migraciones. Resultados de una investigación en Argentina. Mora, (18), 151-166.

MENA MOSQUERA, L. E. (2015). La violencia de género en las mujeres inmigrantes. Tesis de maestría, Facultad de Derecho de la Universidad de Oviedo, Oviedo.

MONTAÑÉS, P. y MOYANO, M. (2006). Violencia de género sobre inmigrantes en España. Un análisis psicosocial. Pensamiento Psicológico, 2(6), 21-32.

MORETT SÁNCHEZ, J y PIZANO, A. (2015). Mujeres migrantes centroamericanas víctimas de violencia de género y de violación de derechos humanos a su paso por México. XXX Congreso de la Asociación Latinoamericana de Sociología. Costa Rica.

PÉREZ OSEGUERA, M. L. et al. (2008). Mujeres migrantes y violencia. Revista Internacional de Ciencias Sociales y Humanidades, XVIII(1), 229-250.

RUIZ, O. (2004). Violencia sexual: el caso de las migrantes centroamericanas en la Frontera Sur. En T. Fernández de Juan, Violencia contra la mujer en México, (pp. 85-98). México DF: Comisión Nacional de Derechos Humanos.

SEGATO, R. L. (2003). Las estructuras elementales de la violencia. Bernal: Universidad Nacional de Quilmes.

SILVA-MARTÍNEZ, E. (2012). Retos para mujeres inmigrantes sobrevivientes de violencia doméstica en nuevos destinos migratorios en Estados Unidos. Migraciones Internacionales, 6(3), 109-138.

SUÁREZ ESCOBAR, M. y DURAND ALCÁNTARA, C. (2014). Migración femenina indígena y la violencia de género. (Algunos estudios de caso en Oaxaca, México). Revista Jurídica de los Derechos Sociales, 4(2), 57-73.

TÁJER, D., GABA, M. y REID, G. (2011). Impacto de la violencia de género en la salud de las mujeres: una investigación en la ciudad de Buenos Aires. Buenos Aires: Informe Final de Investigación del proyecto PNUD-AR. 
WOO MORALES, O. (2004). Abuso y violencia a las mujeres migrantes. En T. Fernández de Juan, Violencia contra la mujer en México (pp. 71-84). México DF: Comisión Nacional de Derechos Humanos.

\title{
Notas
}

1 Este artículo continúa una línea de indagación abierta por una investigación pionera en el tema (Goldberg, 2013) y complementa un trabajo propio publicado en coautoría (Linardelli y Goldberg, 2018).

2 Se refiere al grupo de mujeres "Amarantas tejedoras", un espacio facilitado y coordinado por la Fundación Ecuménica de Cuyo en la localidad de referencia. Se trata de un grupo organizado desde la perspectiva de la educación popular, orientado a la producción de tejidos para venta y el autoconsumo, y tiene como finalidad promover derechos humanos de los/as migrantes.

3 Se refiere a las casas de acogida de la Dirección de Niñez, Adolescencia y Familia de la provincia, habilitadas para niños/as y adolescentes que son separados de sus familias de origen por diversas situaciones de vulneración de derechos.

\author{
Maria Florencia Linardelli \\ linardellimf@gmail.com \\ Doctora en Ciencias Sociales, Universidad Nacional de Cuyo \\ Becaria posdoctoral
}

\section{INCIHUSA-CONICET}

Avenida Ruiz Leal s/n, Parque General San Martín

Ciudad de Mendoza, Mendoza, Argentina

CEP: 5500

\author{
Agradecimentos \\ Agradezco especialmente a cada una de las mujeres migrantes \\ que brindaron sus relatos para esta investigación. \\ Agência financiadora \\ El estudio recibió financiamiento del programa de becas \\ doctorales de CONICET (2014-2019) y formó parte del \\ proyecto Políticas de protección social y salud y trabajo de \\ cuidados. Las relaciones entre la intervención estatal y las \\ experiencias de las mujeres desde una perspectiva crítica \\ de género, en Mendoza a partir de 2009" (PICT 201-0324) \\ financiado por la Agencia Nacional de Promoción Científica y \\ Tecnológica (2017-2021). \\ Contribuições das autoras \\ No aplica.
}

\author{
Aprovação por Comitê de Ética e consentimento para \\ participação \\ Todas las actividades contaron con el consentimiento de las \\ participantes y el proyecto de investigación fue evaluado por la \\ comisión de otorgamiento de becas de CONICET, que incluye \\ la revisión de aspectos éticos.

\section{Consentimento para publicação} \\ En el artículo no se exponen datos de filiación de las \\ entrevistadas que permitan identificarlas, sino que cada una \\ es presentada mediante un seudónimo, a fin de preservar su \\ identidad. Esta estrategia fue consensuada con cada una de las \\ participantes del estudio. \\ Conflito de interesses \\ Sin conflicto de intereses.
}

